\title{
Gender differences in leadership,
} workforce and scholarly presentation within a national society: a gastroenterology perspective

\author{
Alenka J Brooks, ${ }^{1}$ Eleanor Jane Taylor, ${ }^{2}$ E A Arthurs, ${ }^{3}$ Cathryn Edwards, ${ }^{4}$ \\ Richard Gardner, ${ }^{5}$ Melanie Lockett, ${ }^{6}$ Penny J Neild, ${ }^{7}$ Julie Solomon, ${ }^{5}$ \\ Siwan Thomas-Gibson, ${ }^{8}$ Jayne Eaden ${ }^{9}$
}

For numbered affiliations see end of article.

\section{Correspondence to}

Dr Jayne Eaden,

Gastroenterology, University

Hospitals Coventry and

Warwickshire NHS Trust,

Coventry CV2 2DX, UK; jayne.

eaden@uhcw.nhs.uk

This paper was presented as an abstract at the British Society of Gastroenterology meeting in June 2017

Received 4 March 2018 Revised 1 June 2018 Accepted 4 June 2018 Published Online First 7 August 2018

\section{Check for updates}

(C) Author(s) (or their employer(s)) 2019. No commercial re-use. See rights and permissions. Published by BMJ.

To cite: Brooks AJ,

Taylor EJ, Arthurs EA, et al.

Frontline Gastroenterology

2019:10:2-6.

\section{ABSTRACT}

In the UK, gastroenterology has been a male predominant medical speciality. Data regarding gender within workforce, academia and leadership at a national level are lacking.

Data regarding scholarly presentation at the following annual conferences were collected and analysed; British Society of Gastroenterology (BSG) 2013, 2014, and Digestive Diseases Federation (DDF) in 2015.

Data from the 2013-2015 BSG annual workforce reports were examined. In 2015 , female higher specialty trainees (STs) made up 39\% (328/848) of the trainee workforce, versus 37\% and 35\% in 2014 and 2013. From 2013 to 2015, less than a fifth of all consultant gastroenterologists were women. Female consultant (18\%), ST (39\%), associate $(86 \%)$ and student attendance (47\%) at DDF 2015 did not change significantly from 2013 to 2014. Female speakers (trainees and consultants) were significantly lower at DDF 2015 compared with BSG 2014; 43/331 (13\%) versus 56/212 (26.4\%) $(p=0.0001)$ and BSG $201363 / 231$ (27\%) ( $p=0.0001)$. The number of female chairs, delivery of the named lectures and prizes awarded to women did not differ across the 3-year period. Female leadership via representation at Council and Executive at BSG was 4/30 (13\%) in 2015 and did not differ in 2013/2014, with no elected council members since 2008 and one female president in 1973. The proportion of female gastroenterology trainees and consultants is increasing, but remains lower than across all medical specialties and is reflected in attendance and scholarly contributions. Action within the BSG is underway to address female under-representation in leadership roles.

\section{INTRODUCTION}

Since 1991, there have been at least equal numbers of female and male medical students entering medical school in the UK. This has resulted in more female doctors than at any other period in history in the UK, with $45 \%$ of all registered doctors being female, and the proportion of doctors in training who are female is $57 \% .{ }^{1}$ Overall, there has been a $4 \%$ increase in the number of female consultants over the past 4 years with current trainees predominantly being female (52\%). Despite this, female doctors remain significantly under-represented in some medical and most surgical specialties as well as within senior medical leadership roles. ${ }^{2}{ }^{3}$ This disparity continues into salary, with a real term $18 \%$ pay gap between male and female doctors identified in $2009,{ }^{2}$ and when adjusting for confounders, a 5\% gap remains. Women offer a wide range of skills to the National Health Service (NHS) and society and are reported to bring excellent organisational and communication skills to their roles, as well as equal clinical skills, reflected by postgraduate examination pass rates.

Women are also under-represented in clinical academia with barriers to an academic career including lack of flexibility in training, differences in employment practices between institutions, competing training priorities, short-term contracts, geographical complexities in training, being a primary caregiver when hours are antisocial and many more. ${ }^{4}$ As a consequence, Professor Dame Sally Davies, the UK Government's Chief Medical Officer and Director General of 
the National Institute for Health Research, created a Charter that encourages and recognises institutional commitment to advancing the careers of women in science, technology, engineering and mathematics, which has resulted in significant cultural change. ${ }^{5}$ The 'leaky pipeline' identified within academia is also present within the NHS with women doctors being lost along the career path. For example, in 2015, only $52 \%$ of foundation doctors irrespective of gender took up specialty training posts after completing Foundation year $2,{ }^{6}$ a figure that has been falling over the past 5 years. Recent contract re-negotiations in England may potentially worsen equality for female doctors further ${ }^{7}$ leading to a deepening crisis in medical recruitment.

To date, gastroenterology in the UK (which has historically been a male predominant specialty) has not had difficulties with recruitment at specialist registrar and consultant grades. ${ }^{8}$ However, recent data suggest that $48 \%$ of recently advertised gastroenterology consultant posts (September 2015 to August 2016) remain unfilled. ${ }^{9}$ Research into the gender balance of the medical workforce and associated contributions at an academic level are lacking. Demand for gastroenterology services in the UK has been predicted to rise, with a 50\% increase in endoscopic services predicted by $2019 / 2020 .{ }^{10}$ In order to promote and future proof the gastroenterology workforce over the next decade, when female doctors may represent the majority of the medical workforce after $2017,{ }^{2}$ it is imperative we examine and act on the gender differences within the gastroenterology workforce-the reasons for which are complex and vary for different roles and seniority. This includes clinical academia, including scholarly representation, and key leadership roles at a national level and international level where the presence and contribution of female role models may be of significant influence to aspiring women gastroenterologists.

\footnotetext{
Aims

The aims of this study were to examine the gender differences of the workforce in conference attendance and scholarly contribution at a national Gastroenterology conference from 2013 to 2015, and to review the numbers of women in the gastroenterology consultant workforce and in clinical and academic training in the same period. Furthermore, this study aims to examine the numbers of women in BSG leadership roles, defined as an elected role to Council or Executive Leadership Teams.
}

\section{METHODS}

Data regarding scholarly presentation at the BSG 2013, 2014, 2015 annual conferences were collected and analysed. In 2015, this included member societies for the Digestive Diseases Federation (DDF). The member societies included ACPGBI (Association of Coloproctology of Great Britain and Ireland) for which the representation was up to 25\%, AUGIS (Association of Upper Gastrointestinal Surgeons of Great Britain and Ireland) for which the representation was up to 12\%, BAPEN (British Association for Parenteral and Enteral Nutrition) for which the representation was up to $15 \%$, BASL (British Association for the Study of the Liver) for which the representation was up to $10 \%$ and the BSG for which the representation was up to $83 \%$. The data from the 2013-2015 BSG annual workforce reports were examined.

\section{RESULTS}

\section{Workforce and training}

The number of female doctors in substantive consultant posts in 2013 was 209/1255 (17\%), and this increased to $18 \%$ in $2014(236 / 1326)$ and in 2015 $261 / 1414$ (18\%) (see table 1). The number of female gastroenterology trainees was 270/775 (35\%) in 2013, increasing to $312 / 834(37 \%)$ in 2014 and $328 / 850$ $(39 \%)$ in 2015 . The number of female trainees with academic training numbers was $9 / 41(22 \%)$ in 2013, 9/37 (24\%) in 2014 and 10/43 (22\%) in 2015 (see table 1).

\section{Conference attendance}

In 2013, 209/1255 (17\%) of consultant attendance at the DDF conference were women (see figure 1). This is comparative with subsequent years with $236 / 1326$ (18\%) of consultant delegates attending the BSG being women in 2014 and 261/1417 (18\%) in 2015. Female trainee attendance also did not differ over the 3 years studied: 2013, 270/775 (35\%); 2014, 312/833 (37\%); and 2015, 328/848 (39\%). Female associate (including gastrointestinal nurses, dieticians, physiology technicians, nurse consultants and other non-medically qualified individuals) member attendance was not collected in 2013 but was 187/224 (84\%) in 2014 and 322/374 $(86 \%)$ in 2015 . Female student member attendance at annual conferences has increased over the 3-year period: 2013, $15 / 48$ (31\%); 2014, 42/91 (46\%); and 2015, 79/167 (47\%) (see figure 1).

Table 1 Number of female consultants and trainees in Gastroenterology in the UK

\begin{tabular}{llll}
\hline & $2015 \mathrm{n}(\%)$ & $2014 \mathrm{n}(\%)$ & $2013 \mathrm{n}(\%)$ \\
\hline Female consultants: substantive posts & $261 / 1414(18)$ & $236 / 1326(18)$ & $209 / 1255(17)$ \\
Female trainees: national training no & $328 / 850(39)$ & $312 / 834(37)$ & $270 / 775(35)$ \\
Female trainees: academic national training no & $10 / 43(23)$ & $9 / 37(24)$ & $9 / 41(22)$ \\
\hline
\end{tabular}




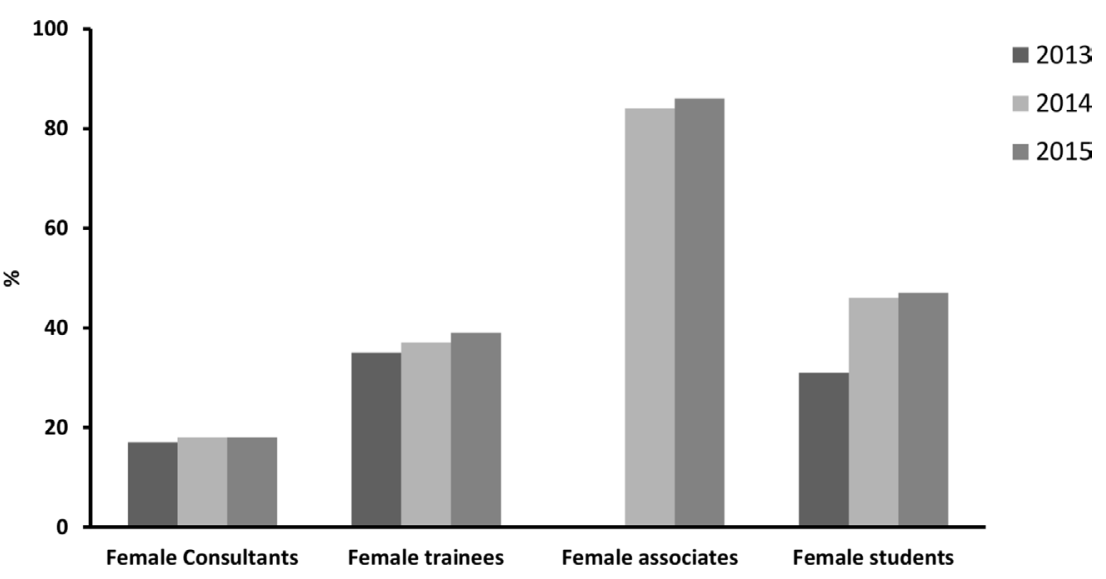

Figure 1 Female attendance by membership type at the British Society of Gastroenterology/Digestive Diseases Federation.

\section{Recognition of scholarly contribution}

In 2013, 6/21 (29\%) of oral prize winners were women compared with $3 / 11(27 \%)$ and $4 / 9$ (44\%) at the 2014 and 2015 BSG, respectively (see table 2). Seven of 25 (28\%) of poster prizes awarded at in 2013 were to women compared with 3/18 (17\%) in 2014 and 6/20 (30\%) in 2015 DDF. Named lectures were given by $1 / 6(17 \%)$ in $2013,1 / 6(17 \%)$ in 2014 and at DDF in 2015 2/15 (13\%). The number of female speakers $(43 / 441,13 \%)$ was significantly lower at DDF in 2015 compared with the BSG conferences in $2013(63 / 167,37.7 \% ; p=0.0001)$ and 2014 (56/212, $26.4 \% ; p=0.0001$ ) (see figure 2). The number of women chairing sessions at conferences was not significantly different with $24 / 89(27 \%)$ in $2013,20 / 94$ $(21.3 \%)$ in 2014 and 23/173 (13\%) in 2015.

\section{Leadership}

Female leadership at the BSG via representation at Executive level was 4/30 (13\%) in 2015 and did not differ in 2013/2014 (see table 3). Furthermore, the BSG has had only one elected female Councillor, elected in 2008. The Society has had one female president in 1973.

\section{DISCUSSION}

The proportion of female gastroenterology trainees and consultants is increasing, but remains lower than that across all medical specialties at 52\% and 34\%, respectively. ${ }^{3}$ Female attendance and scholarly presentation reflects the current workforce of female doctors, but monitoring and action is needed to ensure this continues to rise as the female workforce increases in gastroenterology. The significantly lower numbers

Table 2 Number of female recipients of scholarly recognition

\begin{tabular}{llll}
\hline & $2015 \mathrm{n}(\%)$ & $2014 \mathrm{n}(\%)$ & $2013 \mathrm{n}(\%)$ \\
\hline Female oral prize winners & $4 / 9(44)$ & $3 / 11(27)$ & $6 / 21(29)$ \\
Female poster prize winners & $6 / 20(30)$ & $3 / 18(17)$ & $7 / 25(28)$ \\
Female named lectures & $2 / 15(13)$ & $1 / 6(17)$ & $1 / 6(17)$ \\
\hline
\end{tabular}

of female speakers at DDF 2015 may reflect differences in surgical and allied specialties membership and their related leadership teams. Further data regarding the process of invited speakers for member societies are necessary to further evaluate and address these differences for future joint conferences. Female gastroenterologists are poorly represented at a senior leadership level throughout the Society, and urgent action is needed to address this.

Other specialties have reported similar problems with attracting a balanced gender workforce such as in vascular surgery where the current applicant pool differs from prior generations in their desire for hands-on mentoring, aspirations to affect change daily, a penchant for technology and strong emphasis on work-life balance ${ }^{2}$ Furthermore, the percentage of women pursuing careers in vascular surgery is not representative of the eligible workforce. Women are now the majority of graduates in all of higher education, and thus, vascular surgery may need to make a concerted effort to appeal to women in order to attract the most talented young professionals to the field. ${ }^{2}$ Due to these evolving needs, workforce planning recruitment strategies for both men and women for the current generation need to evolve in order to target a diverse group of potential candidates. Accurate data regarding gender in leadership in the majority other specialities are lacking, but there remain few women medical directors on NHS trust boards, and in 2012 only $16 \%$ of Professors in medicine were women. ${ }^{11}$ This is despite research which repeatedly demonstrates that a gender balance in the boardroom provides less risky and more innovative business approaches. ${ }^{12}$

The NHS needs a workforce that is representative of the populations it serves, with employers having responsibility for investment in the skills and development of employees. ${ }^{13}$ For example, wider structural changes under pinned by strategy and funding are likely to be required to enable diversity in funding, policy and training, as suggested in the House of Commons report. ${ }^{14}$ This 


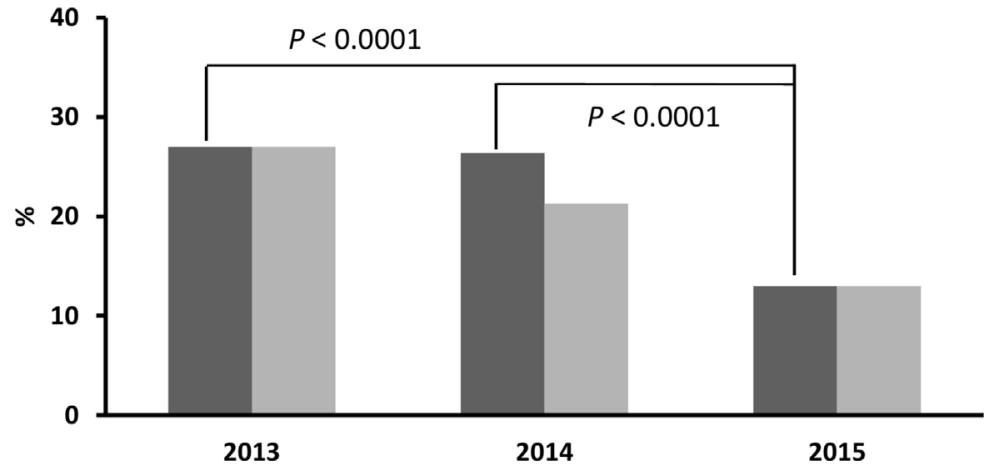

Figure 2 Female speakers and chairs at the British Society of Gastroenterology/Digestive Diseases Federation.

is vital to bring about cultural change within the NHS and wider health service. Following the analysis of data from 2013 to 2015, numerous positive developments have occurred within the Society and wider in Gastroenterology to suggest female leadership is increasing within gastroenterology. These include the second female elected Councillor in 2016, current president elect a female gastroenterologist, female chair of Joint Advisory Group and an increasing proportion of female section chairs at the BSG (2011: 3/23 (15\%); 2012: 4/23 (17\%); 2013: 4/23 (17\%); 2014: 5/23 (22\%); 2015: 5/23 $(22 \%))$. From a wider medical leadership perspective, female leadership is enjoying the limelight with female leaders of the Royal College of General Practitioners, Royal College of Paediatrics, Royal College of Pathologists, Royal College of Physicians, Royal College of Surgeons, Royal College of Radiologists, Royal College of Psychiatrists, Royal College of Obstetricians and Gynaecologists and Chief Medical Officer.

Although these developments are encouraging, further work is needed and the BSG is undertaking significant positive action to address continued female under-representation in gastroenterology as a whole, in scholarly contribution and in leadership roles with a number of innovative schemes. The first of which is the formation of a novel professional network: Supporting Women in Gastroenterology (SWiG) through which key initiatives have been completed. These include a Society-wide survey to understand the factors that may result in under-representation of women in gastroenterology. Alongside this survey, SWiG have led a successful pilot mentoring scheme

\begin{tabular}{|c|c|c|c|}
\hline & 2015 n (\%) & 2014 n (\%) & 2013 n (\%) \\
\hline Female executive seats & $4 / 30(13 \%)$ & $4 / 30(13 \%)$ & $4 / 30(13 \%)$ \\
\hline Elected female councillors & 0 & 0 & 0 \\
\hline
\end{tabular}

for female gastroenterologists, which has resulted in a membership-wide mentoring scheme (in press). SWiG is also supporting women in leadership with an innovate leadership training day, alongside scholarly presentation of data from the mentoring scheme and survey at the BSG. Finally, the Society is implementing strategies to encourage applications from female gastroenterologists to leadership roles within the BSG and ensure that all Society members achieve their potential.

\section{Author affiliations}

${ }^{1}$ Academic Department of Gastroenterology, Sheffield Teaching Hospitals NHS Foundation Trust, Sheffield, UK

${ }^{2}$ Hepatology, St James University Hospital, Leeds, UK

${ }^{3}$ Department of Gastroenterology, Bristol Royal Infirmary, Bristol, UK

${ }^{4}$ Department of Gastroenterology, South Devon NHS Foundation Trust, Torbay, UK

${ }^{5}$ British Society of Gastroenterology, London, UK

${ }^{6}$ Gastroenterology, North Bristol NHS Trust, Bristol, UK

${ }^{7}$ Department of Gastroenterology, St. George's Hospital, London, UK

${ }^{8}$ Wolfson Endoscopy Unit, St Marks Hospital, Harrow, UK

${ }^{9}$ Gastroenterology, University Hospitals Coventry and Warwickshire NHS Trust, Coventry, UK

Contributors $\mathrm{AJB}$ reviewed the literature and prepared the manuscript. EJT collated and analysed data and prepared the manuscript. EAA, CE, RG, ML, PJN, JS, ST-G and JE reviewed manuscript. All authors approved the final draft prior to submission. ML: sponsorship from MSD for workforce talk at generic skills workshop and for ECCO.

Funding The authors have not declared a specific grant for this research from any funding agency in the public, commercial or not-for-profit sectors.

Competing interests None declared.

Patient consent Not required.

Provenance and peer review Not commissioned; externally peer reviewed.

\section{REFERENCES}

1 General Medical Council. The state of medical education and practice in the UK report. 2016. http://www.gmc-uk.org/ publications/somep2016.asp

2 Elston MA. Women and medicine: the future. A report prepared on behalf of the Royal College of Physicians. 2009. www.rcplondon.ac.uk/sites/default/files/documents/womenand-medicine-future-full-report.pdf 


\section{EDUCATION}

3 Gordon H. Census of consultant physicians in the UK 20132014, Executive summary. on behalf of the Royal College of Physicians. https://www.rcplondon.ac.uk/sites/default/files/ 2013-14_rcp_census_exec_summary.pdf

4 Brooks AJ, Ghafur S. 'Inspiring the future': what benefits women in medicine benefits us all. Br J Hosp Med 2014;75:126-7.

5 Munir F. Evaluating the effectiveness and impact of the Athena SWAN charter. http://www.ecu.ac.uk/wp-content/uploads/ external/evaluating-the-effectiveness-and-impact-of-the-athenaswan-charter.pdf

6 The Guardian. Almost half of junior doctors reject NHS career after foundation training. https://www.theguardian.com/ society/2015/dec/04/almost-half-of-junior-doctors-left-nhsafter-foundation-training

7 Department of Health. Equality analysis on the new contract for doctors and dentists in training in the NHS. 2016. https:// www.gov.uk/government/uploads/system/uploads/attachment_ data/file/512696/jd-eia.pdf
8 BSG Workforce Report. 2015. http://www.bsg.org.uk/training/ general/workforce-reports.html

9 BSG workforce Report. 2016 https://www.bsg.org.uk/resource/ workforce-2016.html

10 Cancer Research UK (2015). Scoping the future: an evaluation of endoscopy capacity across the NHS in England. https:// www.cancerresearchuk.org/sites/default/files/scoping_the future_-_final.pdf

11 Medical Schools Council. A survey of staffing levels of medical clinical academics in UK medical schools as at July 2012, 2013.

12 Winning hearts and minds. How CEOs talk about gender parity: Kings College London.

13 NHS. The NHS constitution, the NHS belongs to us all, 2013.

14 House of Commons, Science and Technology Committee. Women in scientific careers. Sixth Report of Session 2013-14, 2014. 